\title{
SPECTRAL ANALYSIS OF NON-SELF-ADJOINT JACOBI OPERATOR ASSOCIATED WITH JACOBIAN ELLIPTIC FUNCTIONS
}

\author{
PETR SiEgL AND FRANTIŠEK ŠTAMPACH
}

\begin{abstract}
We perform the spectral analysis of a family of Jacobi operators $J(\alpha)$ depending on a complex parameter $\alpha$. If $|\alpha| \neq 1$ the spectrum of $J(\alpha)$ is discrete and formulas for eigenvalues and eigenvectors are established in terms of elliptic integrals and Jacobian elliptic functions. If $|\alpha|=1, \alpha \neq \pm 1$, the essential spectrum of $J(\alpha)$ covers the entire complex plane. In addition, a formula for the Weyl $m$-function as well as the asymptotic expansions of solutions of the difference equation corresponding to $J(\alpha)$ are obtained. Finally, the completeness of eigenvectors and Rodriguez-like formulas for orthogonal polynomials, studied previously by Carlitz, are proved.
\end{abstract}

Mathematics subject classification (2010): 47B36, 33E05.

Keywords and phrases: Non-self-adjoint Jacobi operator, Weyl $m$-function, Jacobian elliptic functions.

\section{REFERENCES}

[1] M. Abramowitz AND I. A. STEgun, Handbook of mathematical functions with formulas, graphs, and mathematical tables, vol. 55 of National Bureau of Standards Applied Mathematics Series, U. S. Government Printing Office, Washington, D. C., 1964.

[2] N. I. AKHIEZER, Elements of the theory of elliptic functions, vol. 79 of Translations of Mathematical Monographs, American Mathematical Society, Providence, RI, 1990.

[3] B. BECKERMANN, On the convergence of bounded J-fractions on the resolvent set of the corresponding second order difference operator, J. Approx. Theory 99, 2 (1999), 369-408.

[4] B. Beckermann, Complex Jacobi matrices, J. Comput. Appl. Math. 127, 1-2 (2001), 17-65.

[5] J. Blank, P. Exner and M. HavlíčEK, Hilbert Space Operators in Quantum Physics, 2nd ed. Springer and American Institute of Physics, 2008.

[6] D. BORISOV AND D. KREJČIǨÍK, PT-symmetric waveguides, Integral Equations and Operator Theory 62 (2008), 489-515.

[7] L. CARLiTZ, Some orthogonal polynomials related to elliptic functions, Duke Math. J. 27 (1960), 443-459.

[8] L. CARLitz, Some orthogonal polynomials related to elliptic functions, II, Arithmetic properties, Duke Math. J. 28 (1961), 107-124.

[9] K. Chandrasekharan, Elliptic functions, vol. 281 of Grundlehren der Mathematischen Wissenschaften [Fundamental Principles of Mathematical Sciences], Springer-Verlag, Berlin, 1985.

[10] N. Dunford AND J. T. SChWARTZ, Linear operators, Part II: Spectral theory. Self adjoint operators in Hilbert space, Interscience Publishers John Wiley \& Sons, New York-London, 1963.

[11] D. E. Edmunds And W. D. Evans, Spectral Theory and Differential Operators, Oxford University Press, New York, 1987.

[12] P. Flajolet, Combinatorial aspects of continued fractions, Discrete Math. 32, 2 (1980), 125-161.

[13] P. Flajolet AND J. FrançOn, Elliptic functions, continued fractions and doubled permutations, European J. Combin. 10, 3 (1989), 235-241.

[14] I. S. GRADShTEYN AND I. M. RYZHIK, Table of integrals, series, and products, 6th ed. Academic Press, Inc., San Diego, CA, 2000. 
[15] J. JANAS AND S. NABOKO, Multithreshold spectral phase transitions for a class of Jacobi matrices, in Recent advances in operator theory (Groningen, 1998), vol. 124 of Oper. Theory Adv. Appl., Birkhäuser, Basel, 2001, pp. 267-285.

[16] J. JANAS AND S. NABOKO, Spectral analysis of selfadjoint Jacobi matrices with periodically modulated entries, J. Funct. Anal. 191, 2 (2002), 318-342.

[17] T. Kato Perturbation theory for linear operators, Die Grundlehren der mathematischen Wissenschaften, Band 132, Springer-Verlag New York, Inc., New York, 1966.

[18] R. Koekoek, P. A. LeSky And R. F. SwartTouw, Hypergeometric orthogonal polynomials and their q-analogues, Springer Monographs in Mathematics, Springer-Verlag, Berlin, 2010.

[19] D. KRejČIŘí́x, P. Siegl, M. TATER ANd J. Viola, Pseudospectra in non-Hermitian quantum mechanics, J. Math. Phys. 56 (2015), 103513.

[20] D. F. LAWDEN, Elliptic functions and applications, vol. 80 of Applied Mathematical Sciences, Springer-Verlag, New York, 1989.

[21] S. NABoko, I. Pchelintseva AND L. O. Silva, Discrete spectrum in a critical coupling case of Jacobi matrices with spectral phase transitions by uniform asymptotic analysis, J. Approx. Theory 161, 1 (2009), 314-336.

[22] F. W. J. Olver, Asymptotics and special functions, A K Peters Ltd., Wellesley, MA, 1997.

[23] M. Reed And B. Simon, Methods of modern mathematical physics, I, second ed. Academic Press, New York, 1980.

[24] W. P. REINHARDT AND P. L. WALKER, Jacobian elliptic functions, in NIST handbook of mathematical functions, U. S. Dept. Commerce, Washington, DC, 2010, pp. 549-568.

[25] P. Siegl And F. ŠTAmPaCh, On extremal properties of Jacobian elliptic functions with complex modulus, J. Math. Anal. Appl. 442 (2016), 627-641.

[26] S. Simonov, An example of spectral phase transition phenomenon in a class of Jacobi matrices with periodically modulated weights, in Operator theory, analysis and mathematical physics, vol. 174 of Oper. Theory Adv. Appl., Birkhäuser, Basel, 2007, pp. 187-203.

[27] T. J. Stieltues, Euvres complètes/Collected papers, vol. I, II, Springer-Verlag, Berlin, 1993, reprint of the 1914-1918 edition.

[28] G. TESCHL, Jacobi operators and completely integrable nonlinear lattices, vol. 72 of Mathematical Surveys and Monographs, American Mathematical Society, Providence, RI, 2000.

[29] G. VIENNOT, Une interprétation combinatoire des coefficients des développements en série entière des fonctions elliptiques de Jacobi, J. Combin. Theory Ser. A 29, 2 (1980), 121-133.

[30] P. WALKER, The analyticity of Jacobian functions with respect to the parameter $k, \mathrm{R}$. Soc. Lond. Proc. Ser. A Math. Phys. Eng. Sci. 459, 2038 (2003), 2569-2574.

[31] H. S. WALl, Analytic Theory of Continued Fractions, D. Van Nostrand Company, Inc., New York, N. Y., 1948. 